\title{
Pemrograman Linear Fuzzy dengan Koefisien Teknis Bilangan Fuzzy Menggunakan Metode Fuzzy Decisive Set
}

\author{
Neswin Indara Widiarsi ${ }^{1}$, Rosita Kusumawati ${ }^{2}$ \\ 1,2) Jurusan Pendidikan Matematika, Fakultas MIPA, Universitas Negeri Yogyakarta \\ Karangmalang, Yogyakarta \\ Email: ninda.widiarsi@yahoo.com, rosita_kusumawati@uny.ac.id
}

\begin{abstract}
ABSTRAK
Masalah optimisasi dalam kehidupan sehari-hari tidak semuanya dapat dimodelkan dengan pemrograman linear (PL), khususnya masalah optimisasi dengan kendala yang tidak dapat diukur secara pasti sehingga koefisien teknis dari fungsi kendala tidak dapat dinyatakan secara tegas. Untuk mengatasi hal tersebut, dibutuhkan pemrograman linear fuzzy (PLF). Penyelesaian model PLF dilakukan dengan membawa model PLF ke bentuk PL dengan menentukan batas dari nilai fungsi tujuan serta nilai koefisien teknis model PLF, kemudian mendefinisikan himpunan fuzzy goal dan himpunan fuzzy constraint untuk membentuk himpunan fuzzy decision yaitu irisan dari fuzzy goal dan fuzzy constraint, dan selanjutnya menentukan solusi optimal pada himpunan fuzzy decision dengan memilih elemen dari himpunan fuzzy decision dengan nilai keanggotaan terbesar. Proses ini memuat bentuk non-konveks sehingga metode fuzzy decisive set digunakan. Model PLF diterapkan pada masalah optimisasi UD Firdaus Magelang yaitu memaksimalkan keuntungan penjualan paving dan batako dengan kendala waktu pengadukan, pencetakan, dan pengeringan.
\end{abstract}

Kata kunci: pemrograman linear fuzzy, bilangan fuzzy, metode fuzzy decisive set.

\section{ABSTRACT}

Some of optimization problems in the real life cannot be modelled by linear programming (LP), especially those optimization problems with coefficient technology that cannot be measured surely, so that coefficient technology function cannot be defined strictly. Therefore fuzzy linear programming (FLP) is needed. Steps of FLP are (1) bring the FLP problems into PL problems by determining the bound value of objective function and coefficient technology. (2) defined the fuzzy goal and fuzzy constraint sets to determined fuzzy decision sets. (3) find the optimal solution of fuzzy decision by selecting the member of fuzzy decision sets with the biggest membership value. This proccess contains non convex shape, therefore fuzzy decisive sets is used. FLP model is applied to solve the optimization problems at UD Firdaus Magelang is maximizing profits of paving and brick sales with constraint of mixing, printing, and drying time.

Keywords: fuzzy linear programming, fuzzy numbers, fuzzy decisive set method

\section{Pendahuluan}

Model Pemrograman linear (PL) merupakan suatu model optimisasi yang terdiri dari dua fungsi yaitu fungsi tujuan (objective function) dan fungsi kendala (constraint function) yang berbentuk linear. Fungsi tujuan merupakan fungsi linear mengenai permasalahan yang akan dicari solusi optimalnya, sementara fungsi kendala merupakan fungsi linear yang menyatakan batasan-batasan yang harus dipenuhi dalam mencapai solusi optimal. PL sangat erat hubungannya dengan pengalokasian sumber daya baik berupa bahan baku, tenaga kerja, mesin, maupun modal. Semua sumber daya yang tersedia pada umumnya memiliki jumlah yang sangat terbatas. Oleh karena itu pengalokasiannya harus dilakukan dengan sebaik mungkin untuk mendapatkan hasil yang optimal [6].

Keterbatasan sumber daya terkadang tidak dapat dinyatakan secara pasti. Untuk menyatakan ketidakpastian tersebut diperlukan bilangan fuzzy. Fungsi kendala yang memuat bilangan fuzzy dapat diselesaikan menggunakan pemrograman linear fuzzy (PLF). Terdapat banyak bentuk masalah PLF salah satunya adalah PLF dengan koefisien teknis berbentuk bilangan fuzzy. Jumlah ketersediaan maksimum atas sumber daya dinyatakan secara pasti. 
Masalah PLF dengan koefisien teknis berbentuk bilangan fuzzy diselesaikan dengan mengubah PLF ke bentuk PL. Perubahan bentuk tersebut menghasilakn himpunan penyelesaian layak yang non konveks. Untuk menyelesaikan bentuk permasalahan non konveks diperlukan metode fuzzy decisive set yang dikenalkan oleh Sakawa dan Yana [5].

Beberapa penelitian terkait tentang PLF dengan koefisien teknis berbentuk bilangan fuzzy menggunakan metode fuzzy decisive set di antaranya Rafail N. Gasimov dan Kursat Yenilmez [2] tentang penyelesaian masalah PLF dengan fungsi keanggotaan linear, Rashid Mehmood [5] dalam tesisnya tentang PLF yang diselesaikan menggunakan metode fuzzy decisive set, dan Mohsen Hekmatnia dan Mehdi Allahdadi [3] yang menulis tentang metode baru untuk menyelesaikan masalah PLF.

Salah satu permasalahan optimisasi dengan kendala keterbatasan yang tidak dapat dinyatakan secara tegas adalah masalah optimisasi yang dihadapi oleh UD Firdaus Magelang yaitu memaksimalkan keuntungan penjualan paving dan batako dengan kendala waktu pengadukan, pencetakan, dan pengeringan. Keterbatasan waktu yang digunakan untuk memproduksi paving dan batako tidak dapat dinyatakan secara pasti. Permasalahan pada UD Firdaus Magelang dapat dinyatakan dalam bentuk permasalahan PLF dengan koefisien teknis bilangan fuzzy. berdasarkan uraian di atas, pada artikel ini akan dibahas bagaimana proses menyelesaikan masalah PLF dengan koefisien teknis fungsi kendala berbentuk bilangan fuzzy menggunakan metode fuzzy decisive set, dan penerapannya pada masalah optimisasi UD Firdaus Magelang.

\section{Metode Penelitian}

Penelitian ini dilakukan dengan mempelajari teori dan konsep yang terkait dengan model PLF dan penyelesaiannya, yang kemudian dilanjutkan dengan menerapkan model PLF pada masalah nyata. Adapun kajian teori yang terperlukan dalam pembahasan model PLF dijabarkan di bawah ini.

\subsection{Bilangan Fuzzy}

Himpunan fuzzy pertama kali dikembangkan pada tahun 1965 oleh Zadeh sebagai perluasan dari pengertian himpunan tegas. Himpunan fuzzy adalah himpunan pasangan berurutan dengan elemen pertama adalah elemen himpunan sedangkan elemen kedua adalah derajat keanggotaan dari elemen himpunan. Himpunan fuzzy juga dapat dinyatakan dalam bentuk fungsi keanggotaan. Fungsi keanggotaan (membership function) adalah fungsi yang memasangkan setiap anggota himpunan dengan tepat suatu derajat keanggotaan atau dapat disebut dengan derajat keanggotaan berupa suatu bilangan pada selang antara 0 sampai dengan 1.

Himpunan fuzzy $\tilde{A}$ dikatakan bilangan fuzzy apabila memenuhi sifat normal, $\widetilde{A_{\alpha}}$ merupakan selang tertutup untuk setiap $\alpha \in[0,1]$, serta $\operatorname{Supp}(\widetilde{A})$ adalah selang terbuka, dan konveks [1]. Bilangan fuzzy linear turun adalah salah satu contoh bilangan fuzzy yang dapat direpresentasikan dengan fungsi keanggotaan linear turun sebagai berikut:

$$
\mu_{\tilde{A}}(x)=\left\{\begin{array}{cl}
\frac{(a+d)-x}{(a+d)-a} & , \text { jika } a \leq x \leq a+d \\
0 & , \text { jika } x \geq a+d
\end{array}\right.
$$

\subsection{Pemrograman Linear Fuzzy}

Bentuk umum model PLF adalah sebagai berikut :

$$
\begin{aligned}
& \text { Memaksimalkan } \sum_{j=1}^{n} \tilde{c}_{j} x_{j} \\
& \text { dengan kendala } \sum_{j=1}^{n} \tilde{a}_{i j} x_{j} \leq \tilde{b}_{i}, i=1, \ldots, m
\end{aligned}
$$

dengan

$x_{j} \quad$ : variabel keputusan

$\tilde{a}_{i j} \quad$ : koefisien teknis dalam bentuk bilangan fuzzy

$\tilde{b}_{i} \quad$ : koefisien ruas kanan dalam bentuk bilangan fuzzy

$\tilde{c}_{j} \quad$ : koefisien ongkos dalam bentuk bilangan fuzzy

Terdapat banyak bentuk masalah PLF salah satunya adalah PLF dengan koefisien teknis berbentuk bilangan fuzzy. Masalah PLF dengan koefisien teknis bilangan fuzzy disajikan 
dengan menentukan batasan dan fungsi tujuan yang akan dicapai dari variabel keputusan dalam bentuk pertidaksamaan linear yaitu:

$$
\begin{array}{ll}
\text { Memaksimalkan } \sum_{j=1}^{n} c_{j} x_{j} \\
\text { dengan kendala } \\
\begin{array}{ll}
\sum_{j=1}^{n} \widetilde{a_{\imath j}} x_{j} \leq b_{i} & 1 \leq i \leq m \\
x_{j} \geq 0 & 1 \leq j \leq n
\end{array}
\end{array}
$$

dan $\widetilde{a_{\imath j}}$ adalah bilangan fuzzy.

\section{Hasil dan Pembahasan}

Model PLF (3) dengan koefisien teknis kendala berbentuk bilangan fuzzy diselesaikan berdasarkan teori pengambilan keputusan fuzzy [2] yaitu dengan terlebih dahulu menentukan himpunan fuzzy goal dan fuzzy constraint dari model PLF. Adapun solusi dari model PLF (3) adalah elemen dari himpunan fuzzy decision yaitu irisan dari himpunan fuzzy goal dan fuzzy constraint dengan nilai keanggotaan tertinggi.

Untuk mendefinisikan himpunan fuzzy goal dari model PLF (3), ditentukan terlebih dahulu nilai batas bawah dan batas atas dari nilai yang optimal dari bagian model PLF. Batas dari nilai yang optimal, yaitu $z_{1}$ dan $z_{2}$ didapatkan dari dua bentuk penyelesaian PL sebagai berikut:

$$
z_{1}=\max \sum_{j=1}^{n} c_{j} x_{j}
$$

$$
\begin{aligned}
& \sum_{j=1}^{n} a_{i j} x_{j} \leq b_{i}, i=1, \ldots, m \\
& x_{j} \geq 0, j=1, \ldots, n,
\end{aligned}
$$

dan

$$
\begin{gathered}
z_{2}=\max \sum_{j=1}^{n} c_{j} x_{j} \\
\text { dengan kendala } \\
\sum_{j=1}^{n}\left(a_{i j}+d_{i j}\right) x_{j} \leq b_{i} \\
x_{j} \geq 0,
\end{gathered}
$$

Masalah PLF (3) di atas mempunyai nilai fungsi tujuan optimal berhingga pada selang $z_{1}$ dan $z_{2}$. Dengan $z_{l}=\min \left(z_{1}, z_{2}\right)$ dan $z_{u}=\max \left(z_{1}, z_{2}\right)$. Kemudian $z_{l}$ dan $z_{u}$ disebut batas bawah dan batas atas. Sehingga nilai dari fungsi tujuan terletak di antara keduanya. Sedangkan nilai batas bawah dan batas atas dari nilai koefisien teknis yaitu $a_{i j}$ dan $a_{i j}+d_{i j}$ juga perlu terlebih dahulu ditentukan untuk mendefinisikan himpunan fuzzy constraint dari model PLF (3).

Setelah batas atas dan bawah nilai fungsi tujuan dan kendala model PLF (3) ditentukan, himpunan fuzzy goal dan fuzzy constaraint model PLF (3) dapat didefinisikan dengan fungsi keanggotaan himpunan fuzzy goal $G$ dengan nilai batas atas $z_{u}$ dan batas bawah $z_{l}$ didefinisikan sebagai berikut:

$$
\mu_{G}(x)=\left\{\begin{array}{cl}
0 & , \sum_{j=1}^{n} c_{j} x_{j}<z_{l} \\
\frac{\sum_{j=1}^{n} c_{j} x_{j}-z_{l}}{z_{u}-z_{l}} & , z_{l} \leq \sum_{j=1}^{n} c_{j} x_{j}<z_{u} \\
1 & , \sum_{j=1}^{n} c_{j} x_{j} \geq z_{u}
\end{array}\right.
$$

Kemudian fungsi keanggotaan pada kendala ke $i$ himpunan fuzzy constraint, $C_{i}$ dengan batas atas $a_{i j}+d_{i j}$ dan batas bawah $a_{i j}$ pada koefisien teknis yang didefinisikan sebagai berikut:

$$
\mu_{C_{i}}(x)=\left\{\begin{array}{cc}
0 & , b_{i}<\sum_{j=1}^{n} a_{i j} x_{j} \\
\frac{b_{i}-\sum_{j=1}^{n} a_{i j} x_{j}}{\sum_{j=1}^{n} d_{i j} x_{j}} & , \sum_{j=1}^{n} a_{i j} x_{j} \leq b_{i}<\sum_{j=1}^{n}\left(a_{i j}+d_{i j}\right) x_{j} \\
1 & , b_{i} \geq \sum_{j=1}^{n}\left(a_{i j}+d_{i j}\right) x_{j}
\end{array}\right.
$$


Dengan menggunakan definisi fuzzy decision yang dikenalkan oleh Bellman Zadeh [2] didapatkan irisan dari $\mu_{C_{i}}(x)$ dan $\mu_{G}(x)$ untuk menghasilkan penyelesaian optimal model PLF pada himpunan fuzzy decision $\mu_{D}(x)$ yaitu :

$$
\mu_{D}(x)=\min \left(\mu_{G}(x), \min _{i}\left(\mu_{C_{i}}(x)\right)\right)
$$

Penyelesaian optimal diperoleh dengan mencari elemen dari fuzzy decision dengan nilai keanggotaan terbesar, sehingga didapatkan:

$$
\max _{x \geq 0}\left\{\mu_{D}(x)\right\}=\max _{x \geq 0} \min \left\{\mu_{G}(x), \min _{i}\left(\mu_{C_{i}}(x)\right)\right\}
$$

Ambil $\lambda=\mu_{D}(x)$ sehingga model (3) ekuivalen dengan bentuk :

$$
\lambda=\min \left\{\mu_{G_{j}}(x), \min _{i}\left(\mu_{C_{i}}(x)\right)\right\}
$$

Untuk mendapatkan elemen terbesar dari fuzzy decision, masing-masing dari fuzzy goal dan fuzzy constraint juga harus memiliki nilai $\lambda$ yang maksimum agar bernilai tegas. Dengan demikian, diperoleh :

$$
\begin{aligned}
& \mu_{G}(x) \geq \min \left\{\mu_{G_{j}}(x), \min _{i}\left(\mu_{C_{i}}(x)\right)\right\} \quad \text { atau } \\
& (11) \\
& \mu_{G}(x) \geq \lambda \\
& \operatorname{dan} \\
& \mu_{C_{i}}(x) \geq \min \left\{\mu_{G}(x), \min _{i}\left(\mu_{C_{i}}(x)\right)\right\} \\
& \mu_{C_{\mathrm{i}}}(\mathrm{x}) \geq \lambda, \quad 1 \leq \mathrm{i} \leq \mathrm{m}
\end{aligned}
$$

Model (10) di atas ekuivalen dengan bentuk:

$$
\begin{gathered}
\max \lambda \\
\mu_{G}(x) \geq \lambda \\
\mu_{C_{i}}(x) \geq \lambda \\
x \geq 0 \\
0 \leq \lambda \leq 1
\end{gathered}
$$

Model (13) di atas ekuivalen juga dengan bentuk di bawah ini,

$$
\begin{gathered}
\max { }^{\lambda} \\
\lambda\left(z_{u}-z_{l}\right)-\sum_{j=1}^{n} c_{j} x_{j}+z_{l} \leq 0 \\
\sum_{j=1}^{n}\left(a_{i j}+\lambda d_{i j}\right) x_{j}-b_{i} \\
\leq 0 \\
x_{j} \geq 0 \\
0 \leq \lambda \leq 1
\end{gathered}
$$

Bentuk non-konveks didapat pada langkah mengubah masalah PLF ke bentuk tegas yang memuat perkalian $\lambda x_{j}$ yang terlihat jelas pada persamaan kendala utama pada model 14 di atas. Menurut Ivokhin [4], bentuk tersebut dapat mengakibatkan kendala tidak konveks. Solusi dari masalah ini menggunakan penyelesaian umum non-konveks masalah optimisasi salah satunya dengan metode fuzzy decisive set dengan langkah-langkah sebagai berikut, (1) 
mengambil $\lambda=1$ untuk diselesaikan menggunakan metode simpleks, (2) dilanjutkan dengan menentukan nilai $\lambda=\frac{\lambda^{L}+\lambda^{R}}{2}$ dengan $\lambda^{L}$ dan $\lambda^{R}$ menggunakan metode bagi dua yaitu $\lambda^{L}=\lambda$ jika solusi layak tidak kosong, dan $\lambda^{R}=\lambda$ jika solusi layak kosong.

Model PFL di atas akan digunakan untuk menyelesaikan masalah optimisasi pada UD Firdaus Magelang yang mengandung kendala yang tidak dapat dinyatakan secara tegas. UD Firdaus Magelang merupakan home industri yang memproduksi dua jenis bahan dasar bangunan yaitu paving dan batako. Dalam satu kali pengolahan bahan baku, memerlukan tiga serangkaian proses pengadukan, pencetakan, dan pengeringan. Paving yang dihasilkan dalam satu kali pengolahan adalah sebanyak 150 biji sedangkan batako yang dihasikan dalam satu kali pengolahan adalah sebanyak 80 biji. Satu biji paving memiliki keuntungan 100 rupiah dan 200 rupiah untuk batako. Dengan demikian, keuntungan paving per satu kali pengolahan adalah 15000 rupiah dan keuntungan batako per satu kali pengolahan adalah 16000 rupiah. UD Firdaus Magelang memiliki persediaan waktu 8 jam dalam satu hari kerja dimulai dari pukul 07.00-12.00 dan 13.00-16.00, 6 hari kerja dalam seminggu dan 24 hari kerja dalam satu bulan. Keterbatasan waktu dalam proses pengolahan paving dan batako terlihat seperti pada Tabel 1 .

Tabel 1. Bahan Baku Kebutuhan Produksi dan Toleransi

\begin{tabular}{|l|l|l|l|l|l|}
\hline & \multicolumn{1}{|c|}{ Paving } & \multicolumn{1}{|c|}{ Batako } & $\begin{array}{c}\text { Persediaan } \\
\text { waktu }\end{array}$ & $\begin{array}{c}\text { Toleransi } \\
\text { waktu } \\
\text { paving }\end{array}$ & $\begin{array}{c}\text { Toleransi } \\
\text { waktu } \\
\text { batako }\end{array}$ \\
\hline 1. & $1,5 \mathrm{jam}$ & $1 \mathrm{jam}$ & $8 \mathrm{jam}$ & $0,5 \mathrm{jam}$ & $0,5 \mathrm{jam}$ \\
\hline 2. & $2 \mathrm{jam}$ & $1 \mathrm{jam}$ & $8 \mathrm{jam}$ & 1 jam & $0,5 \mathrm{jam}$ \\
\hline 3. & $4 \mathrm{hari}$ & $3 \mathrm{hari}$ & 24 hari & 1 hari & 1 hari \\
\hline Keuntungan & $\mathrm{Rp} 15000,-$ & $\mathrm{Rp} 16000,-$ & & & \\
\hline
\end{tabular}

Untuk memodelkan masalah UD Firdaus di atas dibentuk $x_{1}$ yaitu banyak pengolahan paving dan $x_{2}$ yaitu pengolahan batako yang dilakukan. Oleh karena itu, perencanaan produksi pada Tabel 1. di atas dapat dirumuskan dalam masalah PL dengan koefisien teknis kendala bilangan fuzzy sebagai berikut:

Memaksimalkan $\mathrm{z}=15000 x_{1}+16000 x_{2}$

Dengan kendala : $\quad \widetilde{1,5} x_{1}+\tilde{1} x_{2} \leq 8$

$$
\begin{aligned}
& \tilde{2} x_{1}+\tilde{1} x_{2} \leq 8 \\
& \tilde{4} x_{1}+\tilde{3} x_{2} \leq 24
\end{aligned}
$$

Sehingga diperoleh,

$$
\begin{gathered}
a_{i j}=\left[\begin{array}{cc}
\widetilde{1,5} & \tilde{1} \\
\tilde{2} & \tilde{1} \\
\tilde{4} & \tilde{3}
\end{array}\right], d_{i j}=\left[\begin{array}{cc}
\widetilde{0,5} & \widetilde{0,5} \\
\tilde{1} & \tilde{1} \\
\tilde{1} & \tilde{1}
\end{array}\right] \\
a_{i j}+d_{i j}=\left[\begin{array}{cc}
\tilde{2} & \widetilde{1,5} \\
\tilde{3} & \tilde{2} \\
\tilde{5} & \tilde{4}
\end{array}\right] \text { dan } b_{i}=\left[\begin{array}{c}
8 \\
8 \\
24
\end{array}\right]
\end{gathered}
$$

Berdasarkan langkah untuk menyelesaikan masalah PLF dengan koefisien teknis kendala berbentuk bilangan fuzzy, dilakukan langkah-langkah sebagai berikut :

1. Menentukan batas dari nilai yang optimal, yaitu $z_{l}$ dan $z_{u}$ yang didapat dari penyelesaian masalah PL.

Memaksimalkan $z_{1}=15000 x_{1}+16000 x_{2}$

dengan kendala : $\quad 1,5 x_{1}+1 x_{2} \leq 8$

$2 x_{1}+1 x_{2} \leq 8$

$4 x_{1}+3 x_{2} \leq 24$

dan memaksimalkan $z_{2}=15000 x_{1}+16000 x_{2}$

dengan kendala : $\quad 2 x_{1}+1,5 x_{2} \leq 8$

$3 x_{1}+1,5 x_{2} \leq 8$ 
Sehingga diperoleh,

$$
5 x_{1}+4 x_{2} \leq 24
$$

$$
\begin{gathered}
Z_{l}=\min \left(Z_{1}, Z_{2}\right)=\min (128000,64000)=64000 \\
Z_{u}=\max \left(Z_{1}, Z_{2}\right)=\max (128000,64000)=128000
\end{gathered}
$$

2. Membawa masalah optimisasi yang sudah ditentukan nilai batas atas dan batas bawah ke dalam bentuk fuzzy goal dan fuzzy constraint untuk mendapatkan fuzzy decision sebagai berikut:

a. Himpunan Fuzzy Goal

$$
\mu_{G}(x)=\left\{\begin{array}{cl}
0 & ; j i k a 15000 x_{1}+16000 x_{2}<64000 \\
\frac{15000 x_{1}+16000 x_{2}-64000}{128000-64000} & ; j i k a 64000 \leq 15000 x_{1}+16000 x_{2}<128000 \\
1 & ; j i k a 15000 x_{1}+16000 x_{2} \geq 128000
\end{array}\right.
$$

b. Himpunan Fuzzy Constraint

$$
\begin{gathered}
\mu_{C_{1}}(x)=\left\{\begin{array}{cc}
0 ; & 8<1,5 x_{1}+1 x_{2} \\
\frac{8-1,5 x_{1}-1 x_{2}}{0,5 x_{1}+0,5 x_{2}} ; & 1,5 x_{1}+1 x_{2} \leq 8<2 x_{1}+1,5 x_{2} \\
1 ; & 8 \geq 2 x_{1}+1,5 x_{2}
\end{array}\right. \\
\mu_{C_{2}}(x)=\left\{\begin{array}{cc}
0 ; & 8<2 x_{1}+1 x_{2} \\
\frac{8-2 x_{1}-1 x_{2}}{1 x_{1}+1 x_{2}} ; & 2 x_{1}+1 x_{2} \leq 8<3 x_{1}+2 x_{2} \\
1 ; & 8 \geq 3 x_{1}+2 x_{2}
\end{array}\right. \\
\mu_{C_{3}}(x)=\left\{\begin{array}{cc}
0 ; & 24<4 x_{1}+3 x_{2} \\
\frac{24-4 x_{1}-3 x_{2}}{1 x_{1}+1 x_{2}} ; & 4 x_{1}+3 x_{2} \leq 24<5 x_{1}+4 x_{2} \\
1 ; & 24 \geq 5 x_{1}+4 x_{2}
\end{array}\right.
\end{gathered}
$$

c. Himpunan Fuzzy Decision

$$
\begin{gathered}
\max \lambda \\
15000 x_{1}+16000 x_{2}-64000 \lambda \geq 64000 \\
(0,5 \lambda+1,5) x_{1}+(0,5 \lambda+1) x_{2} \leq 8 \\
(1 \lambda+2) x_{1}+(1 \lambda+1) x_{2} \leq 8 \\
(1 \lambda+4) x_{1}+(1 \lambda+3) x_{2} \leq 24 \\
0 \leq \lambda \leq 1 \\
x_{1}, x_{2} \geq 0
\end{gathered}
$$

3. Menyelesaikan masalah optimisasi menggunakan fuzzy decisive set dengan algoritma fuzzy decisive set

Tabel 2. Tabel Iterasi

\begin{tabular}{|l|l|l|}
\hline 1. & Untuk $\lambda=1$ & Solusi tidak layak \\
\hline 2. & Untuk $\lambda=0,5$ & Solusi tidak layak \\
\hline 3. & Untuk $\lambda=0,25$ & Solusi layak \\
\hline 4. & Untuk $\lambda=0,375$ & Solusi layak \\
\hline 5. & Untuk $\lambda=0,4375$ & Solusi tidak layak \\
\hline 6. & Untuk $\lambda=0,4063$ & Solusi layak \\
\hline 7. & Untuk $\lambda=0,4219$ & Solusi tidak layak \\
\hline 8. & Untuk $\lambda=0,4141$ & Solusi layak \\
\hline 9. & Untuk $\lambda=0,4180$ & Solusi tidak layak \\
\hline 10 & Untuk $\lambda=0,4161$ & Solusi tidak layak \\
\hline 11. & Untuk $\lambda=0,4151$ & Solusi tidak layak \\
\hline 12. & Untuk $\lambda=0,4146$ & Solusi tidak layak \\
\hline 13. & Untuk $\lambda=0,4144$ & Solusi tidak layak \\
\hline 14. & Untuk $\lambda=0,4143$ & Solusi tidak layak \\
\hline 15. & Untuk $\lambda=0,4142$ & Solusi layak \\
\hline
\end{tabular}


Pada Tabel 2. diperoleh solusi layak pada iterasi ke-15 dengan bentuk fungsi kendala sebagai berikut :

$$
\begin{aligned}
& 15000 x_{1}+16000 x_{2} \geq 90508,8 \\
& 1,7071 x_{1}+1,2071 x_{2} \leq 8 \\
& 2,4142 x_{1}+1,4142 x_{2} \leq 8 \\
& 4,4142 x_{1}+3,4142 x_{2} \leq 24
\end{aligned}
$$

Dengan menggunakan function matlab, diperoleh output exitflag bernilai 1 sehingga terdapat solusi layak atau himpunan layak tidak kosong dengan nilai $x_{1}=0, x_{2}=5,6569$ dan nilai $z=90511,1719$.

\section{Simpulan}

Berdasarkan pembahasan pada masalah PLF dengan koefisien teknis fungsi kendala berbentuk bilangan fuzzy pada studi kasus di UD Firdaus, maka dapat diambil kesimpulan bahwa proses menyelesaikan masalah PLF dilakukan langkah-langkah sebagai berikut membawa masalah ke bentuk PL dengan menentukan nilai batas atas dan batas bawah nilai fungsi tujuan dan nilai koefisien teknis, dilanjutkan dengan mendefinisikan himpunan fuzzy goal dan himpunan fuzzy constraint untuk membentuk himpunan fuzzy decision yang merupakan irisan dari fuzzy goal dan fuzzy constraint, kemudian menentukan solusi optimal pada fuzzy decision adalah elemen dengan nilai keanggotaan terbesar. Himpunan fuzzy decision adalah himpunan fuzzy non-konveks sehingga untuk mencari solusi optimal di dalamnya digunakan metode fuzzy decisive set. Model PLF diterapkan pada masalah optimisasi pada UD Firdaus Magelang untuk memaksimalkan keuntungan penjualan paving dan batako dengan kendala waktu pengadukan, pencetakan, dan pengeringan.

\section{Daftar Pustaka}

[1]. Frans Susilo. (2006). Himpunan dan Logika Kabur Serta Aplikasinya. Yogyakarta: Graha Ilmu.

[2]. Gasimov, Rafail N. dan Kursat Yenilmez. (2002). Solving Fuzzy Linear Programming Problems with Linear Membership Functions. Jurnal Turk J Math, 20, 375-396.

[3]. Hekmatnia, Mohsen \& Mehdi Allahdadi. (2014). New Method for Solving Fuzzy Linear Programming Problem. Jurnal Annals of Fuzzy Mathematics and Informatics, 6.

[4]. Ivokhin, E. V. \& Almodars Barraq Subhi Kaml. (2013). Single-Objective Linear Programming Problems with Fuzzy Coefficients and Resources. Jurnal Journal of Computational and Applied Mathematics, 111, 118-119.

[5]. Mehmood, Rashid. (2009). Thesis Mathematical Modeling and Simulation On Fuzzy Linear Programming Problems Solved with Fuzzy Decisive Set Method. Tesis. Blekenge Tekniska Hogskola.

[6]. Zulian Yamit. (1991). Linear Programming. Universitas Islam Indonesia 
